\title{
Nutritional advice to increase soluble fibre intake does not change plasma folate or homocysteine in men with angina: a randomised controlled trial
}

\author{
Pauline AL Ashfield-Watt, Zoë E Clark, Pat Breay, Paul C Zotos, Sara B Cale, Michael L Burr \\ and lan FW McDowell* \\ Cardiovascular Sciences Research Group (Departments of Medical Biochemistry and Centre for Applied Public \\ Health Medicine), Wales Heart Research Institute, University of Wales College of Medicine, Heath Park, \\ Cardiff CF14 4XN, UK
}

Submitted 27 April 2001: Accepted 20 July 2001

\begin{abstract}
Objective: To study the effect of advice to increase dietary soluble fibre, including fruit and vegetables, on plasma folate and homocysteine in men with angina.

Design: Data were collected on a subset of subjects from the Diet and Angina Randomised Trial (DART II). In a randomised $(2 \times 2)$ factorial design, subjects received advice on either, neither or both interventions to: (1) increase soluble fibre intake to $8.0 \mathrm{~g} \mathrm{day}^{-1}$ (fruit, vegetables and oats); (2) increase oily fish intake to 2 portions week ${ }^{-1}$. Those who received soluble fibre advice were compared with those who did not. Subjects were genotyped for C677T variant 5,10-methylenetetrahydrofolate reductase (MTHFR).

Setting/subjects: Seven hundred and fifty-three male angina patients were recruited from general practice.

Results: Plasma homocysteine concentrations were at the upper end of the normal range (median 11.5, 25\% 9.4, 75\% $14.0 \mu \mathrm{moll}^{-1}$ ). Baseline intake of fruit and vegetables was positively correlated with plasma folate $\left(r_{\mathrm{s}}=0.29, P<0.01\right)$. Smokers had lower intakes of fruit and vegetables, lower plasma folate and higher homocysteine (all $P<0.01$ ). Homozygotes for variant MTHFR had higher homocysteine concentrations at low plasma folate $(P<0.01)$. Reported intakes of fruit and vegetables and estimated dietary folate increased in the intervention group (ca. $+75 \mathrm{~g} \mathrm{day}^{-1}, P<0.01$ and $c a .+20 \mathrm{~g} \mathrm{day}^{-1}, P<0.05$, respectively). However, neither plasma folate (baseline/follow-up 4.5 vs. $4.4 \mu \mathrm{gl}^{-1}, P=0.40$ ) nor homocysteine (baseline/follow-up 11.7 vs. $11.7 \mu \mathrm{moll}^{-1}, P=0.31$ ) changed.

Conclusions: Plasma homocysteine, a cardiovascular risk factor, is influenced by MTHFR genotype, plasma folate and smoking status. Dietary advice successfully led to changes in fruit and vegetable intake, but not to changes in plasma folate or homocysteine, possibly because the fruits and vegetables that were chosen were not those richest in folate.
\end{abstract}

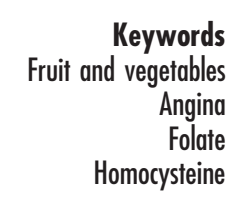

Diets high in fruit and vegetables are associated with reduced risk of chronic diseases including cardiovascular disease $(C V D)^{1}$ and cancer $^{2}$. Suggested mechanisms involve protective roles of specific nutrient intake patterns or associated environment and lifestyle factors. Associations between the nutritional components of fruit and vegetables - antioxidant vitamins and minerals, flavonoids and soluble fibre - and putative mechanisms have been drawn from epidemiological data. Current research increasingly supports a role for folate in prevention of $\mathrm{CVD}^{3}$, cancer ${ }^{4}$ and neural tube defects ${ }^{5}$.

Folate is found in the diet as natural food folates in green leafy vegetables, citrus fruits and dairy products and as synthetic folic acid in fortified foods. It plays an important role in methylation reactions in vivo such as DNA methylation and conversion of homocysteine to methionine. Plasma folate is inversely related to plasma concentrations of homocysteine. Elevated plasma homocysteine is associated with an increased risk of cardiovascular disease. Therefore, it has been proposed that a cardio-protective effect of folate may be mediated by lowering plasma homocysteine ${ }^{3,6}$

Homocysteine concentrations are responsive to lowdose folic acid interventions. Supplementation studies indicate that the homocysteine-lowering capacity of folate reaches a plateau at intakes of around $400 \mu \mathrm{gday}^{-1}$ 
folate ${ }^{6}$. The current UK Reference Nutrient Intake (RNI) for folate of $200 \mu \mathrm{g} \mathrm{day}^{-1}$ is therefore inadequate to achieve maximum homocysteine lowering ${ }^{7}$.

Folate status is influenced by gene-nutrient interactions. A common genetic variant in 5,10-methylenetetrahydrofolate reductase (MTHFR) arising from C677T base substitution leads to a thermolabile enzyme characterised by reduced activity in TT homozygotes. MTHFR converts 5,10-methylenetetrahydrofolate to 5-methyltetrahydrofolate (5meTHF); therefore the TT genotype is associated with reduced concentrations of 5 meTHF, the predominant form of folate in plasma. The gene frequency of this mutation is approximately 0.32 in Caucasian populations, with the TT genotype occurring in $12 \%$ of individuals ${ }^{8}$. MTHFR is a key enzyme in the folate 'methyl transfer' cycle and is associated with elevated homocysteine concentrations in TT homozygotes especially when folate intakes are low. It has therefore been suggested that TT homozygotes have a greater requirement for folate than their CT and CC counterparts?

In published cross-sectional studies, dietary folate intake is inversely associated with homocysteine ${ }^{10}$. Tucker et al. reported that in an elderly USA population fruit and vegetable intakes, particularly green vegetables, are associated with higher plasma folate and lower homocysteine concentrations, an effect that appeared to plateau at 5-6 servings per day ${ }^{11}$. This level of fruit and vegetable consumption equates with current health agency advice to consume 5 portions of fruit and vegetables daily ${ }^{12,13}$ and is consistent with the possible health benefits of these recommendations.

For the majority of the UK population fruit and vegetable intake is approximately $2-3$ portions daily and perceived obstacles such as increased expense and greater preparation time limit the effectiveness of such policies. We therefore investigated the effect of advice to increase fruit and vegetable intakes on folate status in subjects likely to be motivated to follow such dietary advice. We collected data on folate status from angina patients being recruited to an ongoing trial of the effect of increasing soluble fibre intake (increasing fruit, vegetables and oats intakes) on cardiovascular endpoints.

\section{Methodology}

The Diet and Angina Randomised Trial (DART II) is a randomised controlled trial of the effect of dietary interventions to increase oily fish and/or soluble fibre (fruit, vegetables and oats) in a factorial design. Main outcome variables are incidence of myocardial infarction, all-cause mortality, cardiac mortality and sudden death, which will be reported elsewhere. Some 3114 male angina patients were recruited from general practice over a sixyear period. Of these, the last 753 subjects recruited were genotyped for the MTHFR mutation and had cholesterol, total homocysteine (tHcy), plasma folate and vitamin $\mathrm{B}_{12}$ measured at baseline and follow-up visits. Plasma $\beta$ carotene was also measured in a subset (10\%) of subjects who provided detailed dietary information. The nutritional and biochemical data generated from the 753 subjects form the basis of this report. The study was approved by the local research ethics committees.

\section{Patient contact}

Subjects attended their GP surgery or local health authority clinic for assessment by the research nurse and a stateregistered dietitian/nutritionist at baseline and after six months. Each clinical session involved venepuncture, measurement of body mass index (Quetelet index), dietary assessment and dietary advice. Patients were requested to have only a light meal before their appointment, but were not required to fast. Subjects were telephoned after one month and subsequently seen at home by the dietitian. They were also monitored by means of diet diaries during the first two weeks of the study and again after 3 months.

\section{Dietary assessment and interventions}

Ten per cent of subjects were randomly selected to complete a validated, detailed food-frequency questionnaire at baseline and again at the six months follow-up visit. Other subjects completed a short dietary questionnaire. Random allocation to one of four possible dietary interventions was by means of opening a sealed, opaque envelope containing the appropriate dietary code. The dietary interventions included either, neither or both of the two active interventions, namely:

1. oily fish (subjects advised to eat 2 or more main meal size portions of oily fish weekly);

2. soluble fibre (subjects advised to increase intake of fruit, vegetables and oats to achieve an intake of $8 \mathrm{~g}$ soluble fibre daily);

3. interventions 1 and 2 as above;

4. sensible eating advice (control).

The factorial design of the study enabled comparison of each intervention independently, i.e. those receiving oily fish advice vs. those not so advised (groups 1+3 vs. 2+4) or comparison of those receiving soluble fibre advice with those who did not (groups $2+3$ vs. 1+4).

All subjects received postal dietary charts at the intervals described above. These involved recording, over a twoweek period, consumption of those foods relevant to the assigned dietary intervention. For the sensible eating group a record was kept of food eaten from each food group.

\section{Sample processing}

Plasma (EDTA; ethylenediaminetetraacetic acid) was collected for total homocysteine, plasma folate, vitamin $\mathrm{B}_{12}, \beta$-carotene and serum for total cholesterol. EDTA blood samples were centrifuged within $10 \mathrm{~min}$, using a 
portable centrifuge. The plasma was stored in a cool box for up to $4 \mathrm{~h}$ and thereafter stored at $-70^{\circ} \mathrm{C}$ until assayed. Homocysteine was measured by high-performance liquid chromatography (HPLC) ${ }^{14}$ and plasma folate $/ \mathrm{B}_{12}$ by competitive protein binding assay (Abbott IMX). $\beta$ Carotene was assayed by $\mathrm{HPLC}^{15}$. Cholesterol was measured by standard enzymatic methods. For plasma homocysteine and folate, baseline and follow-up samples for each subject were assayed in the same batch to reduce the effect of assay variation (within-batch coefficient of variation $(\mathrm{CV})$ : homocysteine $=2.8 \%$, folate $=4.5 \%$ ) Whole EDTA blood samples were stored frozen for subsequent DNA extraction and MTHFR genotyping ${ }^{8}$.

\section{Statistical analyses}

The a priori hypothesis was that advice to increase soluble fibre would increase plasma folate and reduce homocysteine concentrations. Therefore, the data were stratified by this parameter to produce two groups: soluble fibre vs. no soluble fibre advice. Between-group comparisons at baseline were performed by chi-square tests (categorical variables) and unpaired $t$-tests (continuous variables) and by Mann-Whitney tests (non-parametric data). The effect of dietary intervention was assessed using analysis of covariance (ANCOVA) modelling on treatment with baseline measurement as covariant. Natural logarithms of skewed distributions were used if these approximated the Gaussian distribution. For skewed distributions that were not log-normal, the change from baseline was calculated and the independent samples $t$-test or Mann-Whitney test applied as appropriate. Spearman rank $\left(r_{\mathrm{s}}\right)$ correlation coefficients are reported for skewed data. Effect of genotype and folate status on biochemical variables was assessed using analysis of variance (ANOVA) and Tukey's test post hoc. Data are presented as arithmetic mean (standard deviation (SD)) unless otherwise indicated. For log-normal distributions the geometric mean is presented with the 2.5 and 97.5 percentiles quoted as a measure of dispersion. For consistency, the 2.5 and 97.5 percentiles are also quoted for all other variables in the tables. Analyses were performed using SPSS (SPSS Inc.) version 7.5 .

\section{Results}

Baseline parameters were balanced in the soluble fibre advice and no soluble fibre advice groups (Table 1).

Baseline plasma homocysteine was negatively correlated with plasma folate $\left(r_{\mathrm{s}}=-0.392, P=0.001\right)$. Plasma folate was positively correlated with estimated dietary folate intake $\left(r_{\mathrm{s}}=0.419, P=0.001\right)$ and with dietary fruit and vegetables intake $\left(r_{\mathrm{s}}=0.29, P=0.016\right)$. There was a weak, non-significant trend for plasma homocysteine to be negatively correlated with dietary folate or fruit and vegetables intake $\left(r_{\mathrm{s}}=-0.2, P=0.1\right.$ and $r_{\mathrm{s}}=-0.1, P=$ 0.42 , respectively).

At baseline, stratifying the whole group by MTHFR genotype demonstrated a significant effect of genotype on plasma homocysteine $(P=0.04)$ and plasma folate concentrations $(P<0.001)$. Plasma homocysteine was significantly greater in TT homozygotes than in the CC genotype $(P=0.005)$. CT heterozygotes had intermediate homocysteine concentrations between those of the other two genotypes, producing a TT $>$ CT $>$ CC gradient. The inverse was true for plasma folate, with TT homozygotes having significantly lower plasma folate than their CC counterparts $(P=0.001)$. CT heterozygotes exhibited intermediate plasma folate concentrations that were closer

Table 1 Characteristics of subjects at baseline subdivided by intervention group

\begin{tabular}{|c|c|c|c|c|c|c|}
\hline & \multicolumn{3}{|c|}{ No advice } & \multicolumn{3}{|c|}{ Advice } \\
\hline & $n$ & Mean (SD) & $\begin{array}{c}2.5-97.5 \\
\text { percentiles }\end{array}$ & $n$ & Mean (SD) & $\begin{array}{c}2.5-97.5 \\
\text { percentiles }\end{array}$ \\
\hline Age at randomisation (years) & 372 & $61.0(6.0)$ & $49.2-72.8$ & 381 & $60.9(6.8)$ & $47.6-74.2$ \\
\hline Body mass index $\left(\mathrm{kg} \mathrm{m}^{-2}\right)$ & 370 & $28.7(4.2)$ & $20.5-37.0$ & 376 & $28.4(4.6)$ & $19.3-37.4$ \\
\hline Smokers & $76(20 \%)$ & - & - & $90(24 \%)$ & - & - \\
\hline MTHFR CC & 151 & - & - & 166 & - & - \\
\hline MTHFR CT & 167 & - & - & 163 & - & - \\
\hline MTHFR TT & 50 & - & - & 50 & - & - \\
\hline Dietary folate $\left(\mu \mathrm{g} \mathrm{day}^{-1}\right)$ & 33 & $304.5(82.8)$ & $142.1-466.8$ & 36 & $301.3(82.9)$ & $138.9-463.8$ \\
\hline Fruit and vegetables $\left(\mathrm{g}\right.$ day $\left.^{-1}\right)$ & 33 & $309.1(153.7)$ & $7.8-610.4$ & 36 & $325.9(155.6)$ & $20.9-631.0$ \\
\hline Soluble fibre $\left(\mathrm{g} \mathrm{day}^{-1}\right)$ & 33 & $7.0(2.3)$ & $2.5-11.4$ & 36 & $6.9(2.4)$ & $2.2-11.7$ \\
\hline Vitamin C $\left(\mathrm{mg} \mathrm{day}^{-1}\right)^{\prime}$ & 33 & $81.5(36.0)$ & $10.9-152.1$ & 36 & $77.8(43.9)$ & $8.2-163.7$ \\
\hline Total fat $\left(\mathrm{g} \mathrm{day}^{-1}\right)$ & 33 & $71.6(25.0)$ & $22.5-120.6$ & 36 & $66.0(32.2)$ & $2.86-129.2$ \\
\hline Energy (kcal day ${ }^{-1}$ ) & 33 & $1997.2(414.0)$ & $1185.9-2808.6$ & 36 & $1941.5(627.9)$ & $710.9-3172.1$ \\
\hline Cholesterol $\left(\mathrm{mmoll}^{-1}\right)$ & 371 & $6.3(1.2)$ & $4.0-8.6$ & 380 & $6.2(1.1)$ & $3.9-8.6$ \\
\hline Homocysteine $\left(\mu \mathrm{moll}^{-1}\right) \dagger$ & 372 & 11.8 & $6.3-22.2$ & 381 & 11.7 & $6.5-21.1$ \\
\hline Plasma folate $\left(\mu \mathrm{gl}^{-1}\right) \dagger$ & 372 & 4.5 & $2.0-9.9$ & 381 & 4.5 & $2.1-9.8$ \\
\hline Plasma $B_{12}\left(\mathrm{ngl}^{-1}\right) \dagger$ & 372 & 326.9 & $137.2-778.6$ & 381 & 331.7 & $140.2-784.9$ \\
\hline Plasma $\beta$-carotene $\left(\mu \mathrm{gl}^{-1}\right)$ & 33 & $0.3(0.2)$ & $0.0-0.6$ & 36 & $0.3(0.2)$ & $0.0-0.6$ \\
\hline
\end{tabular}

† Geometric mean presented. 
Table 2 Effect of MTHFR genotype on plasma folate and homocysteine

\begin{tabular}{lccc}
\hline & $\mathrm{CC}(n=317)$ & $\mathrm{CT}(n=330)$ & $\mathrm{TT}(n=100)$ \\
\hline Plasma folate baseline $\left(\mu \mathrm{gl}^{-1}\right)$ & $4.8(2.2-10.4)^{\mathrm{a}}$ & $4.3(2.0-9.1)$ & $4.1(1.7-9.7)$ \\
Plasma folate follow-up $\left(\mu \mathrm{gl}^{-1}\right)$ & $4.7(2.3-9.6)^{\mathrm{b}}$ & $4.4(2.1-9.0)$ & $4.1(1.9-8.7)$ \\
Plasma homocysteine baseline $\left(\mu \mathrm{molI}^{-1}\right)$ & $11.3(6.5-19.7)$ & $12.0(6.6-21.7)$ & $12.6(5.8-27.3)^{\mathrm{c}}$ \\
Plasma homocysteine follow-up $\left(\mu \mathrm{moll}^{-1}\right)$ & $11.4(6.1-21.3)$ & $11.9(6.5-21.9)$ & $12.8(5.6-29.6)^{\mathrm{C}}$ \\
\hline
\end{tabular}

Geometric means and 2.5-97.5 percentiles presented.

For all parameters $P<0.01$ by one-way ANOVA.

${ }^{\mathrm{a}} \mathrm{CC}$ vs. CT and TT, $P<0.01 ;{ }^{\mathrm{b}} \mathrm{CC}$ vs. CT and TT, $P<0.05$; ${ }^{\mathrm{C}} \mathrm{TT}$ vs. CC, $P<0.01$ (by Tukey).

to those of the TT homozygotes. Similar observations were made at follow-up (Table 2). The strongest inverse correlation between plasma homocysteine and plasma folate was observed in the TT individuals (baseline CC: $r_{\mathrm{s}}=-0.39, P=0.001 ;$ СТ: $r_{\mathrm{s}}=-0.33, P=0.001 ;$ ТT: $\left.r_{\mathrm{s}}=-0.49, P=0.001\right)$.

The effect of genotype was most pronounced in subjects with below median plasma folate concentrations. At baseline, when the group was stratified into above and below median plasma folate categories, significant differences in homocysteine between genotypes were observed only in those subjects who had lower plasma folate concentrations $(P=0.009)$ (Fig. 1).

Smokers consumed significantly less fruit and vegetables $(P=0.002)$ and had significantly lower plasma folate $(P<0.001)$ and significantly higher tHcy $(P=$ 0.002) than non-smokers (Table 3 ).

Reported dietary intakes suggested a significant effect of dietary advice to increase soluble fibre on intakes of folate, fruit and vegetables, soluble fibre and total energy intake. However, there was no difference between the advice and no advice groups for plasma folate (advice 4.4 vs. no advice $4.5 \mu \mathrm{gl}^{-1}, \quad P=0.4$ ) or plasma homocysteine (advice 11.7 vs. no advice $12.0 \mu \mathrm{moll}^{-1}, \quad P=0.31$ ).

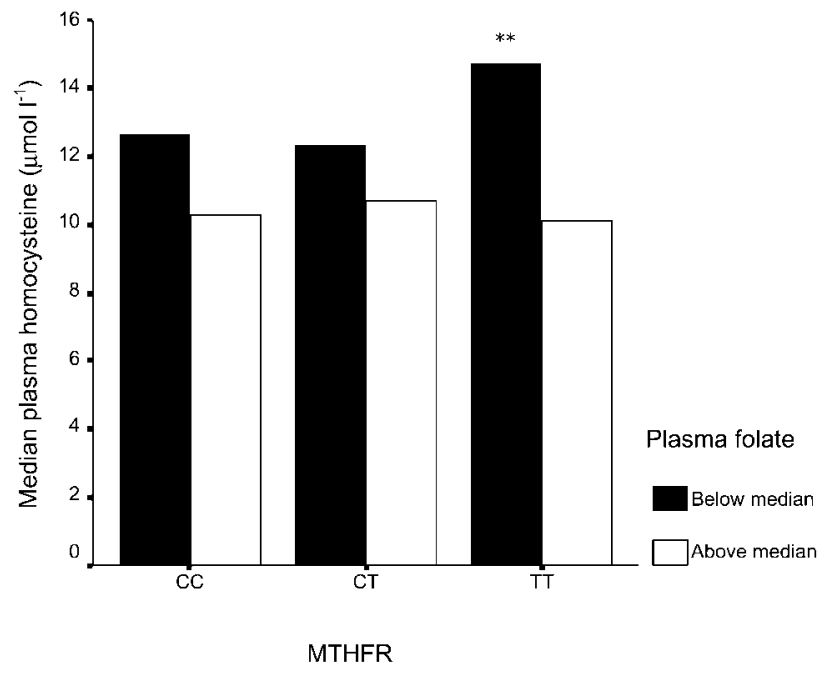

Fig. 1 Effect of plasma folate status and MTHFR genotype on plasma homocysteine at baseline. ${ }^{* *}, P<0.01$ by ANOVA between genotypes in subjects with below median plasma folate only
There was no significant difference in change from baseline between the two groups for either plasma folate (arithmetic mean difference: no advice group -0.01 (SD 1.7), advice group -0.11 (SD 1.6) $\mu g 1^{-1}, P=0.41$ ) or homocysteine (arithmetic mean difference: no advice group -0.25 (3.1), advice group -0.08 (2.8) $\mu \mathrm{gl}^{-1}$, $P=0.43)$. Other biochemical parameters measured vitamin $\mathrm{B}_{12}$, cholesterol and $\beta$-carotene - also did not change (Table 4). There was no significant effect of MTHFR genotype on response to intervention.

\section{Discussion}

The participants in this study were men with coronary heart disease who had high concentrations of cholesterol and homocysteine relative to the general population ${ }^{16}$. Therefore, this is a patient group for whom nutritional and other measures to reduce cardiovascular disease risk are required. The data from this study showed that plasma homocysteine was related to plasma folate, MTHFR genotype and smoking status, but did not respond to dietary advice to increase the intake of soluble fibre, fruit and vegetables.

Genotype for the C677T polymorphism in MTHFR influenced plasma homocysteine and folate concentrations. TT homozygotes had significantly higher tHcy and lower plasma folate concentrations compared with their CT and CC counterparts. These findings confirm that the previously reported effect of MTHFR genotype also applies to this cohort of men with stable angina ${ }^{17,18}$.

There is current controversy regarding the risk of CVD attributable to the MTHFR TT genotype ${ }^{19,20}$. We have previously reported that the TT genotype was not overrepresented in this group of CVD patients when compared with the gene frequency from 604 healthy blood donors from the same geographical area ${ }^{8}$.

At baseline, fruit and vegetable intakes and dietary folate intake were positively and significantly correlated with plasma folate and there was a trend towards weak negative correlations with plasma homocysteine. This is in keeping with previous studies, which have shown that dietary folate intake is strongly correlated with plasma folate concentrations ${ }^{10,21}$ and that sources of dietary folate including fruit and vegetables are correlated with plasma folate and homocysteine concentrations. 
Table 3 Effect of smoking status on plasma folate and homocysteine (at baseline)

\begin{tabular}{lrcrc}
\hline & $n$ & Smokers & $n$ & Non-smokers \\
\hline Plasma homocysteine $\left(\mu \mathrm{moll}^{-1}\right) \dagger$ & 166 & $12.6(6.9-23.0)$ & 578 & $11.6(6.3-21.2)^{\star *}$ \\
Plasma folate $\left(\mu \mathrm{g} \mathrm{I}^{-1}\right) \dagger$ & 166 & $3.7(1.8-7.9)$ & 578 & $4.7(2.2-10.2)^{\star *}$ \\
Fruit and vegetables $\left(\mathrm{g} \mathrm{day}^{-1}\right)$ & 18 & $225.5(117)$ & 51 & $350.5(152.9)$ \\
& & $(3.7-454.7)$ & & $(50.8-650.1)^{\star *}$ \\
\hline
\end{tabular}

† Geometric means and 2.5-97.5 percentiles presented.

${ }^{* *} P<0.01$, independent samples $t$-test.

We observed that plasma folate was significantly lower and homocysteine significantly higher in smokers than in non-smokers. The lower plasma folate concentrations were partly explained by the lower intake of fruit and vegetables in smokers. While lower fruit and vegetable intakes have previously been reported in smokers, there is some evidence that plasma folate may be reduced in smokers even when dietary folate is adequate ${ }^{4}$. Chemical components of tobacco smoke react with certain folates converting them to inactive forms and thereby reduce folate bioavailability ${ }^{4}$.

The reported dietary intakes from food-frequency questionnaires indicated significant increases in fruit and vegetable consumption in the 'advice group', which in turn resulted in significant increases in dietary folate and soluble fibre compared with the control group. However, there was no change in those biochemical measures representative of a change in fruit and vegetable intakes (plasma folate and $\beta$-carotene).

A subgroup analysis did not reveal any effect of MTHFR genotype on change in tHcy in this study, although this may have been due to a lack of change overall. In contrast, we have previously reported that TT homozygotes are more responsive to dietary folate interventions rich in folic-acid-fortified food ${ }^{22}$.

There are several possible explanations for a lack of effect on plasma folate and homocysteine despite the reported increase in dietary folate intake.
- Advice to increase fruit and vegetables is ineffective. The changes in dietary intakes observed are due to reporting bias.

- The change in fruit and vegetable intake was too small to have an important effect on plasma folate or homocysteine because not enough fruits and vegetables were eaten or because the advice given was not specifically targeted towards increasing those fruits and vegetables highest in folate.

- The advice to increase oats was counterproductive, producing a net reduction in folate intake because oats replaced other cereals that were fortified with folic acid.

Food-frequency questionnaires have previously been shown to overestimate intakes of fruit and vegetables so that the intake of nutrients (including folate and fibre) obtained from these sources is also overestimated ${ }^{23,24}$. The baseline weight of fruit and vegetables consumed in this group was apparently higher than the national average and only $80 \mathrm{~g}$ short of that recommended $\left(400 \mathrm{~g} \mathrm{day}^{-1}\right)$ by the World Health Oganization ${ }^{13}$. Although this was a motivated group of subjects who may have been advised to modify their diet on health grounds prior to recruitment, it is unlikely that their overall intake of fruit and vegetables would be so unrepresentative of the rest of the population in South Wales, particularly when a sizeable proportion was from deprived areas where dietary habits are known to be sub-optimal. Therefore, the apparently high intake of

Table 4 Biochemical and nutritional data after intervention with soluble fibre advice

\begin{tabular}{|c|c|c|c|c|c|c|}
\hline & \multicolumn{3}{|c|}{ No advice $(n=372)$} & \multicolumn{3}{|c|}{ Advice $(n=381)$} \\
\hline & $n$ & Mean (SD) & 2.5-97.5 percentiles & $n$ & Mean (SD) & 2.5-97.5 percentiles \\
\hline Body mass index $\left(\mathrm{kg} \mathrm{m}^{-2}\right)$ & 369 & $28.8(4.2)$ & $20.5-37.0$ & 376 & $28.4(4.5)$ & $19.6-37.2$ \\
\hline Dietary folate $\left(\mu \mathrm{g}_{\text {day }}{ }^{-1}\right)$ & 31 & $294(74.1)$ & $148.8-439.2$ & 34 & $322.4(74.6)^{*}$ & $176.1-468.6$ \\
\hline Fruit and vegetables $\left(\mathrm{g}\right.$ day $\left.^{-1}\right)$ & 31 & $300.4(129.0)$ & $47.6-553.3$ & 34 & $400.5(169.5)^{\star *}$ & $68.3-732.8$ \\
\hline Soluble fibre $\left(\mathrm{g} \mathrm{day}^{-1}\right)$ & 31 & $6.7(1.9)$ & $3.0-10.5$ & 34 & $8.3(2.6)^{\star *}$ & $3.2-13.4$ \\
\hline Vitamin C $\left(\mathrm{mg} \mathrm{day}^{-1}\right)^{\prime}$ & 31 & $86.2(43.0)$ & $2.0-170.3$ & 34 & $101.8(48.3)^{*}$ & $7.2-196.4$ \\
\hline Total fat $\left(\mathrm{g} \mathrm{day}^{-1}\right)$ & 31 & $56.4(17.1)$ & $22.5-120.6$ & 36 & $57.6(23.7)$ & $11.0-104.1$ \\
\hline Energy (kcal day ${ }^{-1}$ ) & 31 & $1737.1(312.3)$ & $1125.1-2349.2$ & 36 & $1884.4(496.4)^{\star}$ & $911.5-2857.4$ \\
\hline Cholesterol $\left(\mathrm{mmoll}^{-1}\right)$ & 353 & $6.2(1.1)$ & $4.0-8.4$ & 366 & $6.1(1.1)$ & $4.0-8.2$ \\
\hline Homocysteine $\left(\mu \mathrm{moll}^{-1}\right) \dagger$ & 372 & 12.0 & $6.1-23.3$ & 381 & 11.7 & $6.2-22.1$ \\
\hline Plasma folate $\left(\mu \mathrm{gl}^{-1}\right) \dagger$ & 372 & 4.5 & $2.1-9.5$ & 381 & 4.4 & $2.2-9.1$ \\
\hline Plasma $B_{12}\left(\mathrm{ngl}^{-1}\right) \dagger$ & 372 & 320.7 & $141.2-728.3$ & 381 & 317.6 & $132.7-759.9$ \\
\hline$\beta$-Carotene $\left(\mu \mathrm{gl}^{-1}\right)$ & 33 & $0.3(0.2)$ & $0.0-0.6$ & 36 & $0.3(0.1)$ & $0.0-0.6$ \\
\hline
\end{tabular}

† Geometric mean presented.

Significant difference between groups: ${ }^{*}, P<0.05 ;{ }^{* *}, P<0.01$ by ANCOVA. 
fruit and vegetables at baseline was more likely due to overestimation of dietary consumption than to subjects having already achieved their maximum fruit and vegetable intakes.

The lack of change in any of the biochemical parameters, particularly carotenoids, is suggestive of a difference between reported and actual fruit and vegetable intakes. Over- and underreporting are common in dietary studies where assessment of natural food intakes precludes 'blinding' of subjects. In dietary intervention studies, reporting bias is more likely to occur in the intervention group(s) due to subjects reporting intakes that reflect the advice given by the researcher. It seems likely that some of the change in dietary intake was real, owing to the considerable encouragement subjects had received during the six-month follow-up period which included two contacts plus a home visit by the dietitian. However, it is not possible to determine to what extent overreporting has contributed to the apparent lack of effect of fruit and vegetables on biochemical parameters.

If the food-frequency questionnaire data are at least partially correct, this would suggest that fruit and vegetable intake has no effect on plasma folate or homocysteine. This is in contrast to population studies which have reported that subjects with 'prudent' dietary habits - including plentiful supplies of fruit, vegetables and legumes - have greater dietary folate intakes than individuals with typically 'Western' diets which include few of these foods ${ }^{25}$. In population studies fruits and vegetables are strongly correlated with plasma folate and inversely correlated with plasma homocysteine. Indeed, baseline data from this cohort support these associations.

Naturally occurring folates are easily destroyed during food preparation, processing and storage and have only $50 \%$ bioavailability compared with the synthetic form. Synthetic folic acid, which has greater stability and is easily converted to a bioactive form in vivo, is used as a fortificant in food product manufacture and in supplements. Low-dose folic acid interventions including supplementation and fortification regimens effectively improve folate status ${ }^{22,26}$.

Intervention studies that have investigated the effectiveness of natural folate interventions are scarce and conflicting. Cuskelly et al. ${ }^{27}$ were unable to demonstrate a change in red cell folate following provision of extra natural folate-rich foods $\left(400 \mu \mathrm{g} \mathrm{day}^{-1}\right)$ or dietary advice to increase folate intake from these foods by $400 \mu \mathrm{g} \mathrm{day}^{-1}$. However, the target intakes were not achieved in either group: 201 (117) $\mu \mathrm{gday}^{-1}$ and 92 (73) $\mu \mathrm{gday}{ }^{-1}$, respectively. In contrast, Brouwer et $a l^{28}$ reported a significant increase in red cell folate and a reduction in plasma homocysteine following an intensive dietary intervention involving prepared dishes high in green vegetables and other rich sources of folate, which successfully provided an extra $350 \mu \mathrm{g} \mathrm{day}^{-1}$ folate. These studies would suggest that intensive counselling and specific targeting of folate-rich foods are required to achieve significant changes in folate status. This is in contrast to our study protocol in which fruits and vegetables were part of dietary approach that focused primarily on soluble fibre rather than folate as the target nutrient.

A further possibility for the lack of effect on biochemical factors in this study is therefore that the changes in dietary intakes were too small to produce any detectable change in markers of folate status. An intervention that included specific sources and targets for folate intake may have been more rewarding rather than general advice on fruit, vegetables and oats aimed at improving soluble fibre. Indeed, analysis of the food-frequency data suggest that advice to increase the intake of oats led to a reduction in intake of other cereals, particularly those fortified with folic acid, and could therefore have been counterproductive in terms of increasing folate intake. At baseline, porridge represented $8 \%$ of the cereals eaten in the intervention group compared with $26 \%$ at follow-up. The cereals that the unfortified porridge replaced were those most highly fortified with folic acid (corn flakes and bran flakes fortified at $\left.250 \mu \mathrm{g} \mathrm{day}^{-1}\right)^{29}$.

Given the lack of compliance with advice to increase fruit and vegetables in free-living individuals generally or the self-selection of poor dietary sources of folate even in the case of highly motivated volunteers (as reported here), combined with the poor bioavailability of natural source folates, a more effective means of increasing folate status may be achieved by incorporation of folic-acid-fortified foods. We have previously shown that this approach effectively improves folate status and reduces homocysteine in both hyperlipidaemic patients and healthy individuals ${ }^{22,30}$. Although not mandatory in the United Kingdom, fortified foods especially cereals and breads are widely available and easily incorporated into the diet. If the Committee on Medical Aspects of Food (COMA) recommendations on folic acid fortification of flour products $^{31}$ are implemented, the folate status of the general population is likely to increase without any change in existing dietary habits.

\section{Conclusion}

This study showed that patients with coronary heart disease had raised concentrations of homocysteine, which were related to dietary folate, MTHFR genotype and smoking habit. Patients successfully responded to advice to significantly increase soluble fibre intake, which included increasing fruit and vegetables. However, patients self-selected folate-poor foods that resulted in only a small change in dietary folate intake and no change in either plasma folate or homocysteine concentrations. It can be concluded that public health measures aimed at increasing the intake of these foods are not likely to influence aspects of health related to plasma folate or 
homocysteine. Further research is required to determine whether greater success would be achieved by providing advice to choose specific folate-rich foods and/or folicacid-fortified foods.

\section{Acknowledgements}

This project was funded by The British Heart Foundation, Seven Seas Ltd and Novex Pharma Ltd. The authors would like to thank for their assistance: Mr Paul Phillips, field research; Dr Frank Dunstan, statistical advice; Mr Dick Ellis, haematological measurements.

\section{References}

1 Ness AR, Powles JW. Fruit and vegetables, and cardiovascular disease: a review. Int. J. Epidemiol. 1997; 26: 1-13.

2 Cummings JH, Bingham SA. Diet and the prevention of cancer. Br. Med.J. 1998; 317: 1636-40.

3 Verhoef P, Stampfer MJ, Rimm EB. Folate and coronary heart disease. Curr. Opin. Lipidol. 1998; 9: 17-22.

4 Kim Y-I. Folate and carcinogenesis: evidence, mechanisms, and implications. J. Nutr. Biochem. 1999; 10: 66-88.

5 MRC Vitamin Study Research Group. Prevention of neural tube defects: results of the Medical Research Council Vitamin Study. Lancet 1991; 338: 131-7.

6 Boushey CJ, Beresford SA, Omenn GS, Motulsky AG. A quantitative assessment of plasma homocysteine as a risk factor for vascular disease. Probable benefits of increasing folic acid intakes. JAMA 1995; 274: 1049-57.

7 Department of Health. Dietary Reference Values for Food Energy and Nutrients for the UK. Report on Health and Social Subjects No. 41. London: HMSO, 1991.

8 Clark ZE, Bowen DJ, Whatley SD, Bellamy MF, Collins PW, McDowell IF. Genotyping method for methylenetetrahydrofolate reductase (C677T thermolabile variant) using heteroduplex technology. Clin. Chem. 1998; 44: 2360-2.

9 Harmon DL, Woodside JV, Yarnell JW, McMaster D, Young IS, McCrum EE, Gey KF, Whitehead AS, Evans AE. The common 'thermolabile' variant of methylene tetrahydrofolate reductase is a major determinant of mild hyperhomocysteinaemia. QJM 1996; 89: 571-7.

10 Selhub J, Jacques PF, Wilson PW, Rush D, Rosenberg IH. Vitamin status and intake as primary determinants of homocysteinemia in an elderly population. JAMA 1993; 270: 2693-8.

11 Tucker KL, Selhub J, Wilson PW, Rosenberg IH. Dietary intake pattern relates to plasma folate and homocysteine concentrations in the Framingham Heart Study. J. Nutr. 1996; 126: 3025-1.

12 Committee on Medical Aspects of Food Policy. Nutritional Aspects of Cardiovascular Disease. Report of the Cardiovascular Review Group. London: HMSO, 1994.

13 World Health Organization (WHO). Diet, Nutrition and the Prevention of Chronic Diseases. Report of the WHO Study Group. Technical Report Series 797. Geneva: WHO, 1990.

14 Kuo K, Still R, Cale S, McDowell I. Standardization (external and internal) of HPLC assay for plasma homocysteine. Clin. Chem. 1997; 43: 1653-5.

15 Ho Y, Ochiai J, Saski R, Suzuki S, Kusuhara Y, Morimitsu Y. Serum concentrations of carotenoids, retinol and $\alpha$ tocopherol in healthy persons determined by high performance liquid chromatography. Clin. Chim. Acta 1990; 194: 131-4.

16 Still RA, McDowell IF. Clinical implications of plasma homocysteine measurement in cardiovascular disease. ACP
Broadsheet No. 152: March 1998. J. Clin. Pathol. 1998; 51: $183-8$.

17 Nygard O, Vollset SE, Refsum H, Brattstrom L, Ueland PM. Total homocysteine and cardiovascular disease. J. Intern. Med. 1999; 246: 425-54.

18 Guttormsen AB, Ueland PM, Nesthus I, Nygard O, Schneede J, Vollset SE, Refsum H. Determinants and vitamin responsiveness of intermediate hyperhomocysteinemia ( $>$ or $=40 \mathrm{micromol} / \mathrm{liter}$ ). The Hordaland Homocysteine Study. J. Clin. Invest. 1996; 98: 2174-83.

19 Brattstrom L, Wilcken DE, Ohrvik J, Brudin L. Common methylenetetrahydrofolate reductase gene mutation leads to hyperhomocysteinemia but not to vascular disease: the result of a meta-analysis. Circulation 1998; 98: 2520-6.

20 Kluijtmans LA, Kastelein JJ, Lindemans J, Boers GH, Heil SG, Bruschke AV, Jukema JW, van den Heuvel LP, Trijbels FJ, Boerma GJ, Verheugt FW, Willems F, Blom HJ. Thermolabile methylenetetrahydrofolate reductase in coronary artery disease. Circulation 1997; 96: 2573-7.

21 Jacques PF, Sulsky SI, Sadowski JA, Phillips JC, Rush D, Willett WC. Comparison of micronutrient intake measured by a dietary questionnaire and biochemical indicators of micronutrient status. Am. J. Clin. Nutr. 1993; 57: 182-9.

22 Ashfield-Watt PAL, Pullin CH, Whiting JM, Clark ZE, Moat SJ, Newcombe RN, Burr ML, Lewis ML, Powers HJ, McDowell IFW. Methylenetetrahydrofolate reductase (C677T) genotype modulates blood folate and homocysteine responses to a folate rich diet or low dose folic acid supplement: a randomised controlled trial. Am. J. Clin. Nutr. 2001 [in press].

23 Bingham SA, Gill C, Welch A, Day K, Cassidy A, Khaw KT, Sneyd MJ, Key TJA, Roe L, Day NE. Comparison of dietary assessment methods in nutritional epidemiology: weighed records v. 24h recalls, food-frequency questionnaires and estimated-diet records. Br. J. Nutr. 1994; 72: 619-43.

24 Hu FB, Rimm E, Smith-Warner SA, Feskanich D, Stampfer MJ, Ascherio A, Sampson L, Willett WC. Reproducibility and validity of dietary patterns assessed with a food-frequency questionnaire. Am. J. Clin. Nutr. 1999; 69: 243-9.

25 Hu FB, Rimm EB, Stampfer MJ, Ascherio A, Spiegelman D, Willett WC. Prospective study of major dietary patterns and risk of coronary heart disease in men. Am.J. Clin. Nutr. 2000; 72: 912-21.

26 Brouwer IA, van Dusseldorp M, Thomas CM, Duran M, Hautvast JG, Eskes TK, Steegers-Theunissen RP. Low-dose folic acid supplementation decreases plasma homocysteine concentrations: a randomised trial. Am. J. Clin. Nutr. 1999; 69: 99-104.

27 Cuskelly GJ, McNulty H, Scott JM. Effect of increasing dietary folate on red-cell folate: implications for prevention of neural tube defects. Lancet 1996; 347: 657-9.

28 Brouwer IA, van Dusseldorp M, West CE, Meyboom S, Thomas CM, Duran M, het Hof KH, Eskes TK, Hautvast JG, Steegers-Theunissen RP. Dietary folate from vegetables and citrus fruit decreases plasma homocysteine concentrations in humans in a dietary controlled trial. J. Nutr. 1999; 129: 1135-9.

29 Ministry of Agriculture, Fisheries and Food (MAFF)/Royal Society of Chemistry (RSC). Cereals and Cereal Products. Third Supplement McCance \& Widdowson's The Composition of Foods, 4th ed. London: RSC, 1988.

30 Ashfield-Watt PAL, Knowles RM, Cale SB, Payne N, McDowell IFW. A folate enriched diet lowers plasma homocysteine in patients with hyperlipidaemia: a randomised controlled trial. Br. J. Cardiol. 2001; 8: 28-35.

31 Department of Health. Folic Acid and the Prevention of Disease. Report of the Committee on Medical Aspects of Food and Nutrition Policy. Report on Health and Social Subjects No. 50. London: The Stationery Office, 2001. 